\title{
Gene Therapy for Cystic Fibrosis: Challenges and Future Directions
}

\section{James M. Wilson}

Institute for Human Gene Therapy and Department of Molecular and Cellular Engineering, University of Pennsylvania, and the Wistar Institute, Philadelphia, Pennsylvania 19104

The initial concept of human gene therapy was permanent correction of a recessive disease by transplantation of ex vivo manipulated stem cells (1). An early and still important model for this strategy is treatment of severe combined immunodeficiency due to adenosine deaminase deficiency by bone marrowdirected gene therapy (2). The autosomal recessive disease cystic fibrosis $(\mathrm{CF})^{1}$ was subsequently considered a candidate for gene therapy when the gene responsible for the disease was isolated in 1989 (3-5). The wide distribution of possible cellular targets for gene transfer in the CF lung and the absence of a known lung epithelial stem cell suggested that an ex vivo approach to gene therapy would not be feasible $(6,7)$. Research immediately focused on in vivo approaches for gene transfer that could conveniently be delivered into the airway via aerosols. The ensuing research effort has literally dominated the field of human gene therapy of genetic diseases while establishing the basic principles of in vivo gene delivery. This review summarizes critical scientific issues that have emerged in the development of in vivo gene therapy for CF using adenoviral vectors as a model.

\section{The $C F$ conundrum: relationship between defective ion transport and lung disease}

$\mathrm{CF}$ is an autosomal recessive disease affecting many organs. The pulmonary manifestations of CF are the most morbid and life-limiting aspects of the disease and, therefore, have been the target of most pharmacologic and genetic therapeutic interventions (8). Autopsy analysis of newborn CF patients who died of meconium ileus suggests that the lung is largely unaffected at birth (9). Some time thereafter, patients develop obstructive lung disease and become colonized with pathogenic microorganisms such as Pseudomonas aeruginosa which leads to respiratory infection and chronic airway inflammation (8). The end result is severe bronchiectasis and respiratory failure. A recent survey of CF children who underwent bronchoscopy revealed evidence for inflammation (e.g., increased IL-8 in bronchoal-

Address correspondence to James M. Wilson, M.D., Ph.D., Director, Institute for Human Gene Therapy, 204 Wistar Institute, 3601 Spruce St., Philadelphia, PA 19104-4268. Phone: 215-898-3000; FAX: 215898-6588. 1995.

Received for publication 1 August 1995 and accepted 24 August

1. Abbreviations used in this paper: $\mathrm{BAL}$, bronchoalveolar lavage; $\mathrm{CF}$, cystic fibrosis; CFTR, CF transmembrane conductance regulator; CTL, cytotoxic T lymphocyte; ORCC, outwardly rectifying $\mathrm{Cl}^{-}$channel.

J. Clin. Invest.

(c) The American Society for Clinical Investigation, Inc. 0021-9738/95/12/2547/08 $\$ 2.00$

Volume 96, December 1995, 2547-2554 veolar lavage $[\mathrm{BAL}]$ ) before colonization with pathogenic organisms or onset of clinically overt disease (10).

Important to the rational development of gene therapy for $\mathrm{CF}$ and an assessment of its potential efficacy is an understanding of the underlying pathophysiology of the lung disease. This consideration begins with a description of the molecular and cellular defects in CF. Quinton was the first to note that epithelia from CF patients are relatively impermeable to $\mathrm{Cl}^{-}$, suggesting a primary defect in anion transport (11). Isolation of the gene responsible for CF spawned a number of studies aimed at defining the function of its protein product and role in ion transport (12-14). The 1,480-amino acid open reading frame encoded by this gene has substantial homology to low capacitance transporters such as the multidrug resistance protein, with little structural similarity to known $\mathrm{Cl}^{-}$channels; the protein was therefore named the CF transmembrane conductance regulator (CFTR) (4). The precise role CFTR has in affecting defects in ion transport found in CF epithelia remains unclear despite extensive biochemical and physiological studies. Analysis of purified CFTR in reconstituted lipid bilayers provided unambiguous evidence that it can function as a chloride channel with unique biochemical properties (linear, cAMP-regulated 8-10 $\mathrm{ps} \mathrm{Cl}^{-}$ conductance) (15). It has become clear, however, that CFTR can also regulate a variety of other cationic and anionic channels. A primary defect in CFTR leads to secondary abnormalities in a number of distinct transport processes including increased absorption of $\mathrm{Na}^{+}$via the amiloride-sensitive $\mathrm{Na}^{+}$channel (16), as well as dysregulation of $\mathrm{Cl}^{-}$secretion through both the protein kinase $\mathrm{A}$-responsive outwardly rectifying $\mathrm{Cl}^{-}$ channel (ORCC) (17) and the $\mathrm{Ca}^{2+}$-dependent $\mathrm{Cl}^{-}$channel (18); each secondary abnormality described to date is reversed by complementation of the primary defect in CFTR. A model for CFTR-mediated regulation of the ORCC was suggested recently by Schwiebert et al., who proposed that CFTR transports ATP to the apical surface where it engages the purinogenic receptor transducing an unknown signal to the ORCC (19). This complex web of interactions between multiple channels may explain how the relatively nonabundant CFTR protein could have such a profound effect on the function of epithelia. Implications of these findings on gene therapy are discussed below.

Definition of primary cellular defects responsible for CF lung disease has been difficult to discern because of secondary abnormalities that result from the chronic infections established in childhood. One hypothesis is that the defects in ion transport found in epithelia of conducting airway lead to dehydration of mucus, inspissation of secretions, and defective clearance of inhaled pathogens (8). This elegantly simple hypothesis, however, lacks experimental validation and ignores the complexity of CFTR expression within human lung and the biochemical regulation of the protein. An alternative hypothesis is that the actual macromolecular composition of mucus is perturbed in 


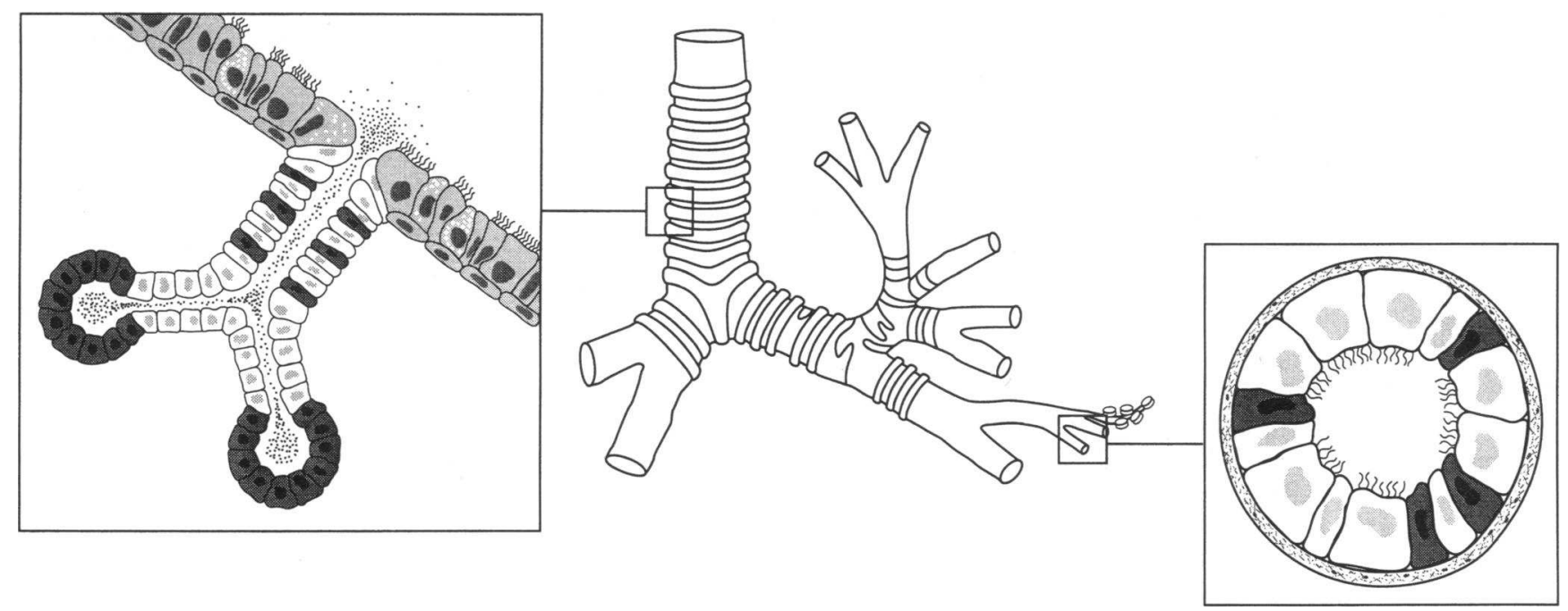

Figure 1. Distribution of CFTR expression in human lung. Presence of CFTR mRNA and protein in cells of human lung was detected by techniques of immunocytochemistry and in situ hybridization. Presence of CFTR epithelial cells is indicated by shading, with intensity proportional to the expression of the gene. The left inset illustrates expression of CFTR in proximal airway. A low level expression is present in most cells of the superficial epithelium, whereas high level CFTR is present in cells of submucosal glands, including serous cells of the distal acini and a subpopulation of cells in the collecting duct. CFTR is found at high levels in a subset of secretory cells in epithelia of distal airway (right inset).

$\mathrm{CF}$, affecting both its rheologic properties and affinity for microbial pathogens such as pseudomonas. Indeed, previous studies have measured increased sulfation of glycoproteins found in $\mathrm{CF}$ mucus (20). The observation that CFTR functions in intracellular components such as in the endoplasmic reticulum (21) and vesicles (22) suggests a mechanism whereby a defective CFTR in secretory epithelial cells could lead to abnormalities in glycoprotein biogenesis.

A detailed analysis of the distribution of CFTR expression in human lung was undertaken to identify targets for gene transfer and to gain insight into pathogenesis $(6,7)$. Fig. 1 presents a summary of CFTR expression in proximal and distal conducting airway as measured by both in situ hybridization and immunocytochemistry. Expression of CFTR is extremely low in superficial epithelia of the proximal airway, as measured by localization techniques and RT-PCR studies that estimated an average of one CFTR transcript per airway epithelial cell $(6,23)$. The predominant site of CFTR expression in proximal conducting airway is in submucosal glands, where high levels of CFTR RNA and protein are found in all cells of serous tubules of the distal gland and in $1-3 \%$ of cells in the more proximal collecting ducts (6). The less complex epithelia of the distal conducting airway, which are void of submucosal glands, contain a subset of surface airway secretory cells $(\sim 2-5 \%)$ that express substantial CFTR (7). This extraordinarily complex program of CFTR expression in human lung has implications for gene therapy. Superficial airway epithelial cells will clearly be more accessible to aerosolized vector than submucosal glands. The therapeutic impact of excluding submucosal glands from genetic reconstitution is unknown, although disease clearly occurs in the substantial network of distal airway where glands do not reside. The other aspect of current strategies for gene therapy of $\mathrm{CF}$ is that the vector and its expression are relatively nonspecific, resulting in ectopic and unregulated expression of CFTR.

Several studies have been undertaken to evaluate the relationship between efficiency of genetic reconstitution and functional correction. The relative sparing of pulmonary disease in CF patients who carry an allele encoding a partially defective
CFTR molecule suggests that less than complete genetic reconstitution will be necessary for therapeutic efficiency (24). The distribution of CFTR expression resulting from gene therapy will be very different from that found in patients with mild mutations, in that high levels of recombinant gene expression will be achieved in a subpopulation of cells likely not the ones that normally express the protein. The relationship between CFTR gene transfer and functional correction has been studied in vitro with polarized primary CF epithelial cells grown on filters and infected with retroviruses or adenoviruses expressing CFTR $(25,26)$. Virtually complete correction of defective chloride secretion across the intact epithelium was achieved with as little as $5 \%$ of the cells transduced. Goldman et al. extended these studies in a more authentic model in which CF bronchial xenografts grown in $n u / n u$ mice are exposed to recombinant adenoviruses; $5 \%$ gene transfer consistently corrected chloride secretion with variable normalization of $\mathrm{Na}^{+}$absorption (27). A similar dose-response relationship was demonstrated in nasal epithelia of CF mice treated in vivo with recombinant adenoviruses (28). The model of CFTR as a regulator of ion transport, which in the case of the ORCC occurs via a diffusible factor, could explain how high level recombinant CFTR expression in a few cells could initiate a cascade of amplifying signals resulting in normalization of function in all cells. These encouraging data suggest incomplete and nondirected gene transfer will correct several aspects of the cellular defect in CF.

\section{Adenoviral vectors as a model for in vivo gene therapy}

The first demonstration of complementation of a CF cell by gene transfer was described in 1990 using recombinant retrovirus and vaccinia virus $(29,30)$. Subsequent work has focused on other viral and nonviral vector systems, including those based on adenoviruses (31), adeno-associated viruses (32), liposomes (33), and molecular conjugates (34). The experience with recombinant adenoviruses in animals and humans is the most advanced and has illustrated principles of in vivo gene therapy for CF. This experience is summarized below.

Human adenoviruses are an attractive vehicle for gene trans- 


\begin{tabular}{|c|c|c|c|c|c|c|c|}
\hline \multirow[b]{2}{*}{ Species } & \multicolumn{3}{|c|}{ Gene transfer } & \multirow[b]{2}{*}{ Inflammation } & \multirow{2}{*}{$\begin{array}{c}\text { Repeat } \\
\text { administration }\end{array}$} & \multirow{2}{*}{$\begin{array}{c}\text { Recovery } \\
\text { of virus }\end{array}$} & \multirow[b]{2}{*}{ References } \\
\hline & Site & Efficiency* & Stability & & & & \\
\hline \multirow[t]{2}{*}{ Adult mouse } & Pulmonary & High (air > alv) & $<21 \mathrm{~d}$ & Yes & No & No & $28,47-49$ \\
\hline & Nasal & Poor & $<14 \mathrm{~d}$ & No & $\mathrm{ND}^{\ddagger}$ & ND & 28 \\
\hline Adult cotton rat & Pulmonary & High (air > alv) & $<21 \mathrm{~d}$ & Yes & No & No & $50-54$ \\
\hline Newborn cotton rat & Pulmonary & High (air > alv) & $>6 \mathrm{mo}$ & No & Yes & ND & Unpublished data \\
\hline \multirow[t]{2}{*}{ Adult baboon } & Pulmonary & High (alv > air) & $<21 \mathrm{~d}$ & Yes & ND & No & $55-57$ \\
\hline & Nasal & Poor & ND & ND & ND & No & Unpublished data \\
\hline Adult rhesus & Pulmonary & High (alv > air) & $<21 \mathrm{~d}$ & Yes & No & Yes & $51,58,59$ \\
\hline Human bronchial xenograft & Pulmonary & Moderate & $>3 \mathrm{mo}$ & No & No & Yes & $27,60,61$ \\
\hline
\end{tabular}

* Efficiency qualitatively described as high, moderate, or poor. Within lung the relative infectibility of alveolar (alv) versus airway (air) is noted.

${ }^{\ddagger}$ Not determined.

fer to airway epithelial cells because of their natural tropism to the respiratory tract and ability to infect nondividing cells (35). This nonenveloped virus is composed of a $36-\mathrm{kb}$ doublestranded DNA genome with three essential early genetic loci encoding critical regulatory proteins (E1, E2, and E4), one nonessential early genetic locus whose expression blocks immune responses to the virus-infected cells (E3), and a series of late genes derived from a large transcript that encodes capsid proteins. E1-deleted recombinant adenoviruses are rendered replication-defective by deleting the immediate early genes, E1a and E1b, believed to be important for replication and activation of other viral genes (36). Recombinant stocks of virus can be grown to high yield in an E1 expressing, trans-complementing cell line such as 293 (37).

The utility of recombinant adenoviruses for lung-directed gene transfer was demonstrated by Crystal and colleagues in the cotton rat, an animal model used in the study of adenoviral pneumonia $(31,38)$. Intratracheal instillation of E1-deleted viruses containing recombinant genes, such as human CFTR, resulted in high level transgene expression in a substantial number of intrapulmonary airway epithelial cells. These studies have been repeated by other investigators in the cotton rat and extended to additional animal species, including mouse and nonhuman primates. Table I summarizes the salient features of this work and appropriate references. Gene transfer is consistently high in the lung with some variation noted in the relative efficiency of gene transfer to alveolar versus conducting airway epithelial cells. More recent studies suggest that the volume of instilled virus may have a role in distribution of gene transfer within lung, with larger volumes favoring an alveolar distribution. In all models except newborn cotton rat and the human bronchial xenograft, expression of the transgene is transient and associated with a dose-dependent, biphasic, and self-limited inflammatory response. Very little recombinant virus was recovered after gene transfer, except in the bronchial xenograft and in some nonhuman primate studies. The efficiency of gene transfer was diminished in virtually all models after repeated administrations of virus.

Clinical trials have been initiated by six independent groups using a variety of protocols based on nasal and/or lung-directed gene transfer (39-43). The goal of these phase I studies is to evaluate safety and efficiency of gene transfer. Protocols based on gene transfer to nasal epithelia provide an excellent opportunity for assessing gene transfer; however, the relevance of the data to intrapulmonary epithelia has been questioned. The major problem with the lung-directed studies is assessment of gene transfer efficiency which requires molecular analyses of bronchial epithelial cells recovered at bronchoscopy; difficulties in obtaining representative samples render negative studies difficult to interpret. Although the data are still preliminary, some interesting trends have emerged. Gene transfer has been documented in lung with $\sim 10^{7}$ plaque forming units (pfu) of virus in both the Cornell/NIH (44) and University of Pennsylvania trials (unpublished data). Nasal epithelia seem much more resistant to gene transfer based on the University of North Carolina trial, which required $10^{10} \mathrm{pfu}$ virus to achieve $\sim 1 \%$ gene transfer (45). The Iowa/Genzyme group reported partial and transient correction of $\mathrm{Cl}^{-}$transport in nasal epithelia at lower doses of virus (46), although these studies may have been complicated by injury to the epithelia at the time of virus administration, which could artifactually enhance the efficiency of gene transfer. Preliminary data on the safety of recombinant adenoviruses in humans will be discussed below.

\section{Immunologic barriers to gene therapy}

The promise of recombinant adenoviruses for efficient in vivo gene transfer must be buoyed by the consistent problems of inflammation and loss of transgene expression that have characterized their use in virtually all preclinical models, including adult mice $(28,47-49)$, cotton rats $(50-54)$, and nonhuman primates $(51,55-59)$. Two experimental models that have not demonstrated these problems, the human bronchial xenograft $(27,60,61)$ and newborn cotton rat (unpublished data), suggest that host immune responses may be involved. This was formally evaluated by instilling E1-deleted adenoviruses into trachea of different strains of mice including $C 57 B L / 6$ and derivative strains that are deficient in cellular and humoral immunity (i.e., $n u / n u$ and $R A G 2^{-1-}$ ). Recombinant gene expression was high in all animals at day 3, but dropped to undetectable levels with concurrent inflammation in C57BL/6; transgene expression was stable (i.e., at least $12 \mathrm{mo}$, Yang, Y., and J. Wilson, unpublished results ) with less inflammation in the immune-deficient strains $(47,62)$.

Many experiments have been performed in mice to define 


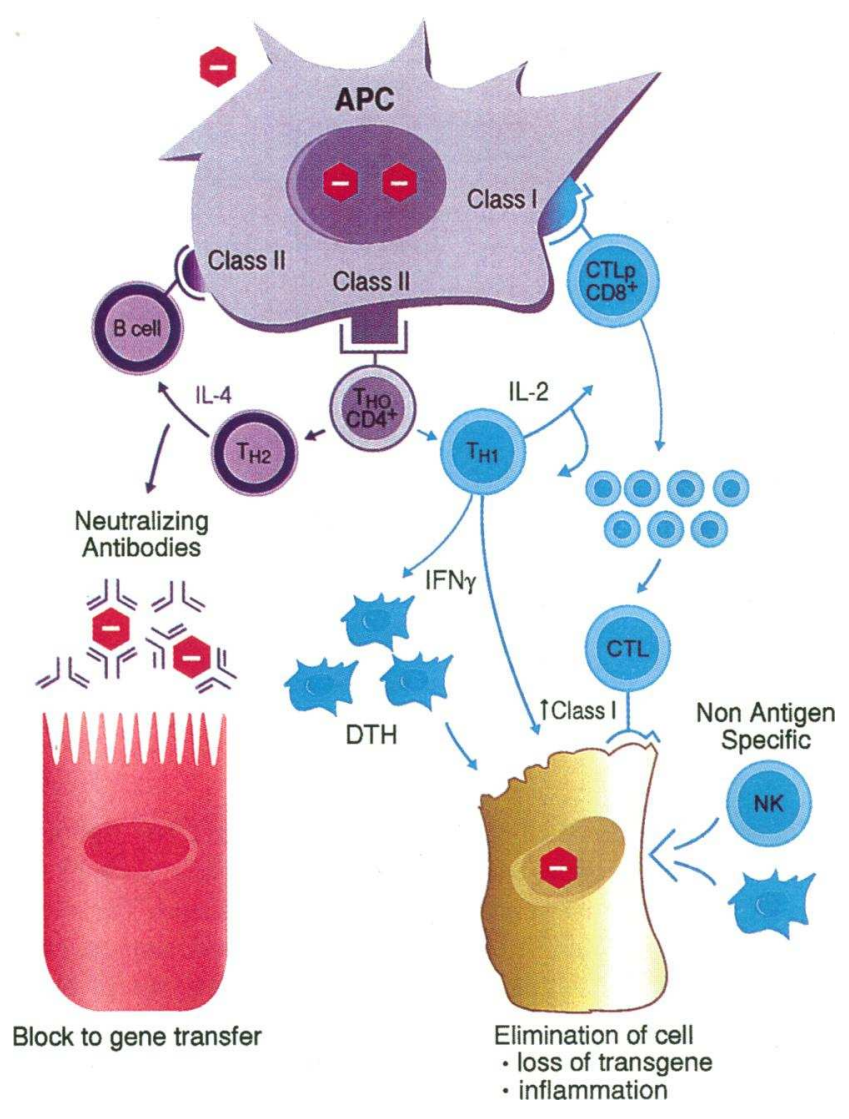

Figure 2. Immune responses to adenovirus-mediated gene transfer. Antigens are presented by the antigen presenting cell $(A P C)$ to activate cellular immunity (blue) and humoral immunity (purple) with the end result being destruction of target cell and block to gene transfer, respectively. $D T H$, delayed type hypersensitivity; and $N K$, natural killer cell.

the specific immune responses that underlie the observations made in immune-competent animals. We speculated that host responses, which are appropriately mobilized to combat viral pathogens, may be present, albeit in an attenuated way, when recombinant viruses are administered for gene therapy. Principles learned in the field of viral pathogenesis were applied to our studies of adenovirus-mediated gene transfer to lung, a model of which is presented in Fig. 2.

Identification of virus-specific cytotoxic $\mathrm{T}$ lymphocytes (CTLs) as potential immune effectors was suggested initially by in vitro ${ }^{51} \mathrm{Cr}$ release assays. Lymphocytes harvested from BAL and mediastinal lymph nodes of adenovirus-treated C57BL/6 mice were shown to specifically lyse MHC-compatible target cells infected with the recombinant adenovirus ( 47 , 48). This led to the hypothesis that CTLs are activated to newly synthesized viral proteins or the transgene product in an MHC class I-restricted manner which directly or indirectly destroys the target cell or destabilizes the transgene. The appreciation that early and late viral genes are expressed in airway epithelial cells infected with E1-deleted viruses provided further credibility to this hypothesis (47). Evidence to support this has been derived from knockout mice and adoptive transfer techniques in both liver- and lung-directed models of gene transfer. Transgene expression is stabilized in animals deficient in CD8 cells and MHC class I by virtue of a germ line $\beta 2 \mathrm{~m}^{-}$interruption (48). Specific ablation of perforin, the molecule on CTLs and NK cells that mediates cytolysis, yields a similar prolongation of transgene expression (unpublished results). Further support for the role of $\mathrm{CD}^{+}$cells in transgene instability was provided in experiments where $\mathrm{CD} 8^{+}$cells from treated $C 57 B L / 6$ animals were adoptively transferred into $R A G 2^{-1-}$ animals stably expressing the adenovirus-encoded transgene (48). After adoptive transfer, $\mathrm{CD}^{+}$cells rapidly infiltrated lung, and transgene expression was ablated. While these experiments point to antigenspecific CTLs as important effectors, they do not necessarily define the mechanisms of transgene elimination (e.g., target cell destruction and turnover, mobilization of secondary effectors, destabilization of transgene, etc.) or the relative contribution of viral and transgene epitopes to CTL activation. We have evidence that CTL to some transgene products do indeed develop; however, CTL to viral proteins are sufficient to eventually subvert the therapy (63). Studies performed to date do not rule out non-antigen-specific factors or other antigen-specific processes also contributing to the loss of transgene. In fact, similar techniques were used in these models to show the emergence of functionally significant class I-restricted, viral-specific CD4 ${ }^{+}$ CTLs (64).

Models of viral pathogenesis have demonstrated an essential role of $\mathrm{CD}^{+}{ }^{+}$cells in the costimulation and/or augmentation of primary antiviral effectors. This principle was confirmed in mouse models of adenovirus-mediated gene transfer to liver (65) and lung (reference 49 and Yang, Y., and J. M. Wilson, manuscript submitted for publication) where it was shown that transgene expression persists in animals made deficient of $\mathrm{CD} 4{ }^{+}$cells by genetic interruption or antibody depletion. $\mathrm{CD} 4^{+}$ cells could participate in the destruction of virus-infected cells in several ways. Proteins from the input virus are presented by MHC class II to T helper cells that differentiate into either $T_{H 1}$ subsets, which secrete IL-2 and IFN- $\gamma$, or $\mathrm{T}_{\mathrm{H} 2}$ subsets, which secrete a variety of cytokines including IL-4 (Fig. 3) (66). $T_{\mathrm{H} 1}$ have a primary role in regulation of several effectors capable of eliminating the viral genome. One mechanism is activation of macrophages by IFN- $\gamma(67,68)$ or costimulation of CTL activation by IL-2 $(69,70)$. In addition, secretion of IFN- $\gamma$ by $T_{H 1}$ cells could enhance CTL activity by increasing MHC class I presentation of antigen on the infected cell $(71,72)$. Analysis of lymphocytes from $C 57 B L / 6$ mice infected with E1-deleted virus documented the activation of $T_{\mathrm{H} 1}$ cells to viral proteins (48). The critical role of IFN- $\gamma$ was demonstrated in animals

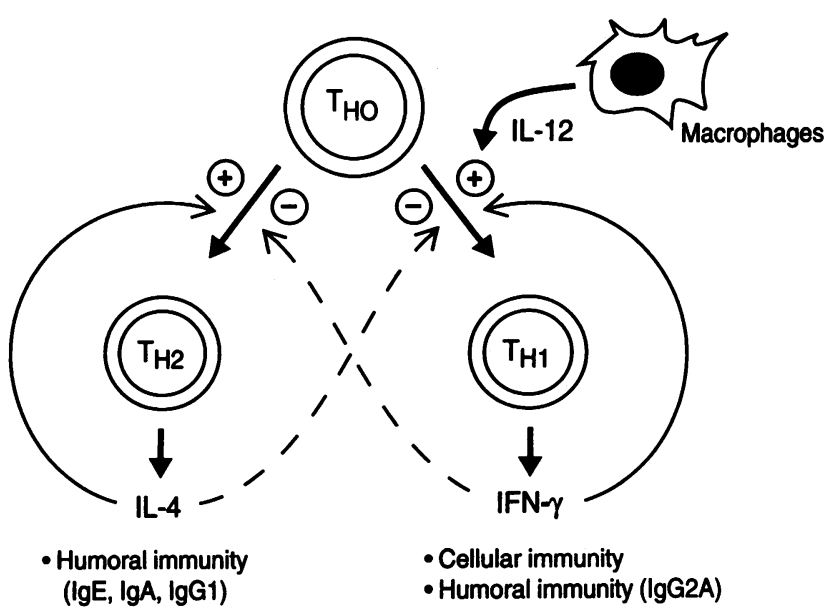

Figure 3. Cytokine regulation of $\mathrm{T}$ helper cell differentiation. Adapted from reference 66 
deficient in this cytokine (IFN- $\gamma$ " "knockout" or antibody-depleted) in whom recombinant adenoviral transgene expression was stabilized (reference 65 and Yang, Y. and J. M. Wilson, manuscript submitted for publication). Upregulation of MHC class I that occurred in the targeted organ after administration of virus was blocked in animals deficient in IFN- $\gamma(65)$. These studies suggest that one role $T_{\mathrm{H} 1}$ cells could have in augmenting the CTL response is through enhancement of class I-mediated antigen presentation. The response of immune-competent mice to adenovirus-mediated gene transfer varies with the genetic background of the animal, suggesting that MHC variation may impact on vector performance and safety (73).

The motivation for delineating mechanisms of host responses to virus-infected cells is to develop rational strategies to prevent those that subvert the therapy. One approach is to modify the vector to minimize or eliminate expression of viral proteins so as to avoid activation of CTLs and/or recognition of target cell by CTLs. It is clear that deletion of E1 alone is insufficient to prevent expression of early and late genes and to render the virus totally replication-defective (47). The most effective strategy to disable the adenovirus is to delete all of its viral open reading frames. In fact, this is possible using helper virus to trans-complement the fully deleted vector (reference 74 and Fisher, K. J., J. Burda, S.-J. Chen, and J. M. Wilson, manuscript submitted for publication). Low yield of recombinant virus and contamination of the stock with helper virus have limited the utility of this approach (Fisher, K. J., J. Burda, S.-J. Chen, and J. M. Wilson, manuscript submitted for publication). A more feasible approach is to isolate E1-deleted recombinants in which a subset of the remaining essential genes is rendered defective by additional deletion or temperature-sensitive mutations. The availability of new packaging cell lines that stably express multiple essential genes will greatly facilitate the isolation of these recombinants. Our first experience with this approach incorporated a temperature-sensitive mutation into the E2a gene of an E1-deleted virus $(47,54,57)$. This virus is associated with diminished late viral gene expression, less pathology, and modest but variable improvements in transgene stability. The concern is that, despite inactivation of all early genes, the major late promoter will have basal activity sufficient to elicit problematic cellular immune responses. Under these circumstances, it may be necessary to incorporate into the vector genes that suppress MHC class I presentation of antigens. Many DNA viruses have evolved this type of function to escape immune surveillance. Examples include the $19-\mathrm{kD}$ E3 gene product of adenovirus (75), the ICP47 gene from herpes simplex virus (76), and the USII gene from human cytomegalovirus (77).

Recognition that $T_{\mathrm{H} 1}$ activation is necessary for a fully functional CTL response suggested another therapeutic strategy for avoiding cellular immune responses that extinguish transgene expression. This strategy is based on the premise that $T_{\mathrm{H} 1}$ cells are activated to input virion proteins which are presented by MHC class II but rapidly cleared after the administration of therapy. We reasoned that coadministration of agents that block $T_{\mathrm{H} 1}$ activation with virus should stabilize transgene expression far beyond the period of transient immune blockade. This concept has been validated in mouse models of adenovirus-mediated gene transfer to lung by coadministration of the general cytotoxic drug cyclophosphamide (unpublished data) and the more specific immune modulator anti-CD4 monoclonal antibody (49). Other potential agents include inhibitors of $\mathrm{T}$ cell costimulation (e.g., anti-CD40L monoclonal antibody [78] or
CTLA4-Ig [79]) and cytokines that inhibit activation of $T_{H 1}$ cells such as IL-4 (Fig. 3).

The other major immune barrier to successful adenovirus gene therapy of lung is the humoral responses to adenovirus that develop subsequent to gene therapy. Capsid proteins from the input virus are processed by antigen-presenting cells and presented to T helper and B cells by MHC class II leading to the formation of antiviral antibodies which neutralize the virus and prevent it from entering the cell. The net result is difficulty in achieving efficient gene transfer upon a second administration of virus $(48,49,52)$. Unfortunately, more defective viruses will be of little help because the antigenic stimulus for antibody production is capsid proteins of the delivered virus. Strategies described above which attempt to interrupt $T$ helper cell activation to capsid protein at the time of virus delivery, such as cyclophosphamide (unpublished data) and anti-CD4 monoclonal antibody (49), do indeed prevent neutralizing antibody formation and allow successful repeated gene therapy. A more selective strategy was developed based on differential activation of the $T$ helper subsets, $T_{\mathrm{H}_{1}}$ and $\mathrm{T}_{\mathrm{H} 2}$, and the role they play in isotype switching. The primary immunoglobulin responsible for neutralization of adenovirus in the airway is $\operatorname{IgA}$ which is dependent on $\mathrm{T}_{\mathrm{H} 2}$ cells for its production (49). Based on the known cytokine regulation of $T$ helper cell differentiation (Fig. 3), we developed a strategy to prevent the activation of $\mathrm{T}_{\mathrm{H} 2}$ cells using IFN- $\gamma$ or IL-12 (which activates $\mathrm{T}_{\mathrm{H} 1}$ cells to secrete IFN- $\gamma$ ) to inhibit $\mathrm{T}_{\mathrm{H} 2}$ differentiation (49). Coadministration of either cytokine at the time of virus instillation did prevent formation of antiviral IgA and allowed efficient readministration of virus. The advantage of this strategy to prevent neutralizing antibody must be balanced, however, with the disadvantage of potentially enhancing CTL-mediated events through activation of $\mathrm{T}_{\mathrm{H} 1}$ cells. Another approach which should be evaluated is to interfere with the molecular interactions of costimulation necessary to activate the CD4 T cells. Examples include CTLA4-Ig (79) and an antibody to CD40 ligand (78).

\section{Efficacy versus toxicity: therapeutic index}

A critical evaluation of any proposed genetic therapy is an assessment of therapeutic index: the dose of vector that provides therapeutic efficacy in the absence of toxicity. Multiple factors will contribute to therapeutic index, including the efficiency and distribution of gene transfer, direct toxic effects of the virus, and antigen- and non-antigen-specific responses of the recipient to the vector and/or genetically modified cell.

Adenoviruses were selected as appropriate vehicles for lungdirected gene therapy because the spectrum of diseasës that result from naturally acquired infections (i.e., pharyngitis, upper respiratory infections, and pneumonias) would suggest that the virus is tropic for airway epithelia (35). Therefore, it is ironic that concerns have been raised about the efficiency with which recombinant adenoviruses transfer genes to airway epithelia $(28,45)$. One consistent observation has been that epithelial cells in a fully differentiated epithelium are more resistant to adenovirus-mediated gene therapy than when they are dispersed in culture $(28,80)$. Actual in vivo assessments of functional correction in animals and humans have been restricted for technical reasons to nasal epithelia. Very high doses of virus were required to achieve only partial correction of $\mathrm{Cl}^{-}$transport, as measured by mucosal potential difference, in nasal mucosa of CF mice (28). The experience in nasal epithelia of CF patients has been similarly disappointing (45).

A more comprehensive review of the preclinical and clinical 
data, together with an understanding of the biology of adenovirus entry, indicates that adenovirus-mediated gene transfer in human lung may be more efficient than what was achieved in the nose. In the two models where direct comparisons were made, i.e., mouse (28) and baboon (unpublished data), adenovirus-mediated gene transfer was substantially more efficient in intrapulmonary epithelia than in nasal epithelia. Similarly high level gene transfer was demonstrated in epithelia within the lung of rhesus monkeys $(51,58,59)$ and cotton rats $(50$ $54)$. The limited data available in humans suggest a similar discordance with the demonstration of low level gene transfer after intrabronchial instillation with lower doses of virus $\left(\sim 10^{6}\right.$ $\mathrm{pfu}$ ) in patients of two independent trials (unpublished data and reference 44) despite difficulty in nasal epithelia with the same or similar virus $(45)$.

A greater understanding of the rate-limiting steps in adenovirus-mediated transduction would help assess feasibility and potentially suggest strategies for improvement. The hypothesis we have pursued is based on viral entry as the limiting step in gene transduction. Wickham et al. described a two-step process for entry of adenovirus, based on binding of fiber to a cellular receptor, followed by an internalization-dependent interaction between a cellular $\alpha_{\mathrm{v}} \beta$ integrin and the RGD motif on the penton base (81). Data in bronchial human xenografts suggest that transfer of recombinant adenovirus into differentiated airway epithelial cells is limited by expression of the cellular $\alpha_{v} \beta$ integrin (80). A survey of human lung tissues revealed essentially no $\alpha_{\mathrm{v}} \beta$ protein in differentiated cells of nasal and proximal airway epithelia, consistent with the difficulties in achieving gene transfer in these structures, and high level $\alpha_{\mathrm{v}} \beta$ in all differentiated epithelial cells of distal noncartilagenous airway (Goldman, M. J., and J. M. Wilson, manuscript submitted for publication). These experiments would predict much higher gene transfer in distal human lung than that achieved in nasal epithelia.

Safety concerns with recombinant adenoviruses have focused on replication of the virus and inflammation at the site of therapy with potential systemic consequences. Little is known about the pathogenesis of a naturally acquired adenovirus infection in humans; however, Ginsberg and colleagues have used the cotton rat, which is permissive for replication of Ad5 in lung, as well as the mouse, which is nonpermissive, as models for human adenovirus pneumonia (82-84). A story of pathogenesis has emerged that describes an early non-antigen-specific phase occurring 2-3 d after infection that is cytokine dependent (TNF- $\alpha$, IL-1, and IL-6) and dominated by polymorphonuclear leukocytes, which is followed by a $\mathrm{T}$ celldependent mononuclear-dominated response that is dependent on viral protein expression.

An extensive body of data has accumulated regarding the toxicity associated with administration of E1-deleted adenoviruses into the airway of animals. Several consistent findings have emerged from studies performed by multiple investigators in a number of species including mouse, cotton rat, rhesus monkey, and baboon (see Table I). There is dose-dependent inflammation at the site of gene transfer that diminishes without permanent sequelae. When carefully examined, the response of the recipient resembles the biphasic pathology seen with replication-competent virus in cotton rats, which initially is dominated by neutrophils quickly transitioning into a mononuclear-predominant histology. The pathology noted at necropsy can be detected clinically as an infiltrate on chest radiographs and an increase in lymphocytes in BAL, although the animals have generally tolerated the virus well with few systemic manifestations. There has been little evidence for dissemination and/ or shedding of virus.

Despite extensive work on the immunology of adenovirusmediated gene transfer to lung and the evaluation of a large number of animals in toxicology protocols, little is known about the mechanisms that contribute to the inflammatory responses seen in animals or their relevance in humans. There will likely be at least three components to inflammation seen with higher doses of virus including toxic effects of the virus, non-antigenspecific inflammation to the virus, such as that mediated by NK cells, and antigen-specific activation of T cells (CTL and T helper) and possibly B cells. The fact that administration of inactivated virus is associated with detectable inflammation in the mouse confirms the importance of processes which are independent of virus replication or viral protein expression (85). The experience with intrapulmonary instillation of virus in patients has been limited but largely unremarkable at the low doses administered to patients. The one patient who received high-dose virus $\left(\sim 10^{9} \mathrm{pfu}\right)$ is an illustrative exception (44). Within $12 \mathrm{~h}$ of administration of virus, she developed fever, hypotension, multilobar infiltrates, and a significant rise in serum IL-6. The intensity and rapidity of onset of this syndrome were not predicted by the animal experiments. This could be explained by species differences or the influence of preexisting immunity to adenoviruses that is endemic in the human population.

\section{Future directions}

The development of adenoviral vectors for gene therapy of $\mathrm{CF}$ has accelerated the concept of in vivo gene delivery. Lessons learned in the early experiments will likely be generic to in vivo gene therapy with other vectors in different diseases. It is not surprising that host immune responses develop to the vector and genetically corrected cells which try to subvert the therapeutic intervention. A better understanding of host-vector interactions will be essential when designing rational strategies to prevent these confounding problems. Animal studies performed to study these mechanisms primarily have used inbred strains of pathogen-free animals. Predicting effectiveness of therapy in the human population will be more challenging due to substantial heterogeneity in both antigen presentation, based on MHC allelic variation, and the intensity and nature of the immune response, based on previous exposure to adenovirus.

The fact that viral pathogens have evolved strategies to escape immune surveillance (i.e., persistence or latency) should be exploited in the design of second generation therapies. Another approach is to implement adjunctive therapies that modulate the recipients' immune responses to the therapy. Early human pilot experiments that test concepts developed in animal models will be critical in focusing research toward the goal of a cure. This is particularly important when developing strategies to circumvent host responses.

In anticipation of the development of safe and efficient vector systems, the field should prepare for the difficult task of assessing efficacy. The importance of this is reinforced by the likely development of multiple gene transfer technologies in parallel and the need to make early priority decisions. A better understanding of basic pathophysiology of $\mathrm{CF}$ with the further development of animal models would be very useful in establishing surrogate endpoints for clinical efficiency. In the absence of such surrogates, important decisions regarding development of effective therapies will defer to phase III trials which are 
costly and use the most precious resource, which is the pool of patients eligible for clinical trials.

\section{Acknowledgments}

I want to thank members of my laboratory for their input and critical review of this manuscript.

This work was supported by the Cystic Fibrosis Foundation and the National Institute of Diabetes and Digestive and Kidney Diseases and the National Heart, Lung, and Blood Institute of the National Institutes of Health.

\section{References}

1. Anderson, W. F. 1984. Prospects for human gene therapy. Science (Wash. DC). 226:401-409.

2. Kohn, D. B., K. I. Weinberg, J. A. Nolta, L. N. Heiss, C. Lenarsky, G. M. Crooks, M. E. Hanley, G. Annett, J. S. Brooks, A. El-Khoureiy, et al. 1995. Engraftment of gene-modified umbilical cord blood cells in neonates with adenosine deaminase deficiency. Nature Medicine. 1:1017

3. Rommens, J. M., M. C. Iannuzzi, B. Kerem, M. L. Drumm, G. Melmer, M. Dean, R. Rozmahel, J. L. Cole, D. Kennedy, N. Hidaka, et al. 1989. Identification of the cystic fibrosis gene: chromosome walking and jumping. Science (Wash. DC). 245:1059-1065.

4. Riordan, J. R., J. M. Rommens, B. Kerem, N. Alon, R. Rozmahel, Z. Grzelczak, J. Zielenski, S. Lok, N. Plavsic, J.-L. Chou, et al. 1989. Identification of the cystic fibrosis gene: cloning and characterization of complementary DNA. Science (Wash. DC). 245:1066-1073.

5. Kerem, B., J. M. Rommens, J. A. Buchanan, D. Markiewicz, T. K. Cox, A. Chakravarti, M. Buchwald, and L.-C. Tsui. 1989. Identification of the cystic fibrosis gene: genetic analysis. Science (Wash. DC). 245:1073-1080.

6. Engelhardt, J., J. Yankaskas, S. Ernst, Y. Yang, C. Marino, R. Boucher, J. Cohn, and J. Wilson. 1992. Submucosal glands are the predominant site of CFTR expression in the human bronchus. Nat. Genet. 2:240-248.

7. Engelhardt, J., M. Zepeda, J. Cohn, J. Yankaskas, and J. Wilson. 1994. Expression of the cystic fibrosis gene in adult human lung. J. Clin. Invest. 93:737749.

8. Welsh, M. J., L.-C. Tsui, T. F. Boat, and A. L. Beaudet. 1995. Cystic fibrosis. In The Metabolic and Molecular Bases of Inherited Disease. Vol. III. C. R. Scriver, A. L. Beaudet, W. S. Sly, and D. Valle, editors. McGraw-Hill Inc., New York. 3799-3876.

9. Sturgess, J., and J. Imrie. 1982. Quantitative evaluations of the development of tracheal submucosal glands in infants with cystic fibrosis and control infants. Am. J. Pathol. 106:303-311.

10. Khan, T. Z., J. S. Wagener, T. Bost, J. Martinez, F. J. Accurso, and D. W. Riches. 1995. Early pulmonary inflammation in infants with cystic fibrosis. Am. J. Respir. Crit. Care Med. 151:1075-1082.

11. Quinton, P. 1983. Chloride impermeability in cystic fibrosis. Nature (Lond.). 301:421-422.

12. Kartner, N., J. W. Hanrahan, T. J. Jensen, A. L. Naismith, S. Sun, C. A. Ackerley, E. F. Reyes, L.-C. Tsui, J. M. Rommens, C. E. Bear, and J. R. Riordan. 1991. Expression of the cystic fibrosis gene in non-epithelial invertebrate cells produces a regulated anion conductance. Cell. 64:681-691.

13. Drumm, M. L., D. J. Wilkinson, L. S. Smit, R. T. Worrell, T. V. Strong R. A. Frizzell, D. C. Dawson, and F. S. Collins. 1991. Chloride conductance expressed by $\Delta$ F508 and other mutant CFTRs in Xenopus oocytes. Science (Wash. DC). 254:1797-1799.

14. Cheng, S. H., D. P. Rich, J. Marshall, R. J. Gregory, M. J. Welsh, and A. E. Smith. 1991. Phosphorylation of the R domain by cAMP-dependent protein kinase regulates the CFTR chloride channel. Cell. 66:1027-1036.

15. Bear, C. E., C. Li, N. Kartner, R. J. Bridges, T. J. Jensen, M. Ramjeesingh, and J. R. Riordan. 1992. Purification and functional reconstitution of the cystic fibrosis transmembrane conductance regulator (CFTR). Cell. 68:809-818.

16. Stutts, M. J., C. M. Canessa, J. C. Olsen, M. Hamrick, J. A. Cohn, B. C. Rossier, and R. C. Boucher. 1995. CFTR as a cAMP-dependent regulator of sodium channels. Science (Wash. DC). 269:847-850.

17. Gabriel, S. E., L. L. Clarke, R. C. Boucher, and M. J. Stutts. 1993. CFTR and outwardly rectifying chloride channels are distinct proteins with a regulatory relationship. Nature (Lond.). 363:263-266.

18. Grubb, B. R., R. N. Vick, and R. C. Boucher. 1994. Hyperabsorption of $\mathrm{Na}^{+}$and raised $\mathrm{Ca}^{2+}$-mediated $\mathrm{Cl}^{-}$secretion in nasal epithelia of CF mice. Am. J. Physiol. 266:C1478-C1483.

19. Schwiebert, E. M., M. E. Egan, T.-H. Hwang, S. B. Fulmer, S. S. Allen, G. R. Cutting, and W. B. Guggino. 1995. CFTR regulates outwardly rectifying chloride channels through an autocrine mechanism involving ATP. Cell. 81:10631073.

20. Cheng, P.-W., T. F. Boat, K. Cranfill, J. R. Yankaskas, and R. C. Boucher.
1989. Increased sulfation of glycoconjugates by cultured nasal epithelial cells from patients with cystic fibrosis. J. Clin. Invest. 84:68-72.

21. Foskett, J. K., and D. C. P. Wong. 1994. $\left[\mathrm{Ca}^{2+}\right]_{\mathrm{i}}$ inhibition of $\mathrm{Ca}^{2+}$ release-activated $\mathrm{Ca}^{2+}$ influx underlies agonist- and thapsigargin-induced $\left[\mathrm{Ca}^{2+}\right]_{\mathrm{i}}$ oscillations in salivary acinar cells. J. Biol. Chem. 269:31525-31532.

22. Barasch, J., B. Kiss, A. Prince, L. Saiman, D. Gruenert, and Q. Al-Awqati. 1991. Defective acidification of intracellular organelles in cystic fibrosis. Nature (Lond.). 352:70-73.

23. Trapnell, B. C., C. S. Chu, P. K. Paakko, T. C. Banks, K. Yoshimura, V. J. Ferrans, M. S. Chernick, and R. G. Crystal. 1991. Expression of the cystic fibrosis transmembrane conductance regulator gene in the respiratory tract of normal individuals and individuals with cystic fibrosis. Proc. Natl. Acad. Sci. USA 88:6565-6569.

24. Gan, K.-H., H. J. Veeze, A. M. W. van den Ouweland, D. J. J. Halley, H. Scheffer, A. van der Hout, S. E. Overbeek, J. C. de Jongste, W. Bakker, and H. G. M. Heijerman. 1995. Evidence of a cystic fibrosis mutation associated with mild lung disease. N. Engl. J. Med. 333:95-99.

25. Johnson, L. G., J. C. Olsen, B. Sarkadi, K. L. Moore, R. Swanstrom, and R. C. Boucher. 1992. Efficiency of gene transfer for restoration of normal airway epithelial function in cystic fibrosis. Nat. Genet. 2:21-25.

26. Zabner, J., L. A. Couture, A. E. Smith, and M. J. Welsh. 1994. Correction of cAMP-stimulated fluid secretion in cystic fibrosis airway epithelia: efficiency of adenovirus-mediated gene transfer in vitro. Hum. Gene Ther. 5:585-593.

27. Goldman, M., Y. Yang, and J. Wilson. 1995. Gene therapy in a xenograft model of cystic fibrosis lung corrects chloride transport more effectively than the sodium defect. Nat. Genet. 9:126-131.

28. Grubb, B., R. Pickles, H. Ye, J. Yankaskas, R. Vick, J. Engelhardt, J. Wilson, L. Johnson, and R. Boucher. 1994. Inefficient gene transfer by adenovirus vector to cystic fibrosis airway epithelia of mice and humans. Nature (Lond.). 371:802-806.

29. Drumm, M., H. Pope, W. Cliff, J. Rommens, S. Marvin, L. Tsui, F. Collins, R. Frizzell, and J. Wilson. 1990. Correction of the cystic fibrosis defect in vitro by retrovirus-mediated gene transfer. Cell. 62:1227-1233.

30. Rich, D. P., M. P. Anderson, R. J. Gregory, S. H. Cheng, S. Paul, D. M Jefferson, J. D. McCann, K. W. Klinger, A. E. Smith, and M. J. Welsh. 1990. Expression of cystic fibrosis transmembrane conductance regulator corrects defective chloride channel regulation in cystic fibrosis airway epithelial cells. Nature (Lond.). 347:358-363.

31. Rosenfeld, M. A., K. Yoshimura, B. C. Trapnell, K. Yoneyama, E. R. Rosenthal, W. Dalemans, M. Fukayama, J. Bargon, L. E. Stier, L. StratfordPerricaudet, et al. 1992. In vivo transfer of the human cystic fibrosis transmembrane conductance regulator gene to the airway epithelium. Cell. 68:143-155.

32. Flotte, T. R., S. A. Afione, C. Conrad, S. A. McGrath, R. Solow, H. Oka P. L. Zeitlin, W. B. Guggino, and B. J. Carter. 1993. Stable in vivo expression of the cystic fibrosis transmembrane conductance regulator with an adeno-associated virus vector. Proc. Natl. Acad. Sci. USA 90:10613-10617.

33. Caplen, N. J., E. W. F. W. Alton, P. G. Middleton, J. R. Dorin, B. J. Stevenson, X. Gao, S. R. Durham, P. K. Jeffery, M. E. Hodson, C. Coutelle, et al. 1995. Liposome-mediated CFTR gene transfer to the nasal epithelium of patients with cystic fibrosis. Nature Med. 1:39-46.

34. Ferkol, T., C. S. Kaetzel, and P. B. Davis. 1993. Gene transfer into respiratory epithelial cells by targeting the polymeric immunoglobulin receptor. J. Clin. Invest. 92:2394-2400.

35. Horwitz, M. 1990. Adenoviridae and their replication. In Virology. B. Fields, editor. Raven Press, New York. 1679-1721.

36. Berkner, K. L. 1988. Development of adenovirus vectors for the expression of heterologous genes. Biotechniques. 6:616-629.

37. Graham, F., J. Smiley, W. Russell, and R. Nairn. 1977. Characteristics of a human cell line transformed by DNA from human adenovirus 5. J. Gen. Virol. 36:59-72.

38. Rosenfeld, M. A., W. Siegfried, K. Yoshimura, K. Yoneyama, M. Fukayama, L. E. Stier, P. K. Paakko, P. Gilardi, L. D. Stratford-Perricaudet, M. Perricaudet, et al. 1991. Adenovirus-mediated transfer of a recombinant $\alpha 1$-antitrypsin gene to the lung epithelium in vivo. Science (Wash. DC). 252:431-434.

39. Crystal, R. G., A. Jaffe, S. Brody, A. Mastrangeli, N. G. McElvaney, M. Rosenfeld, C.-S. Chu, C. Danel, J. Hay, and T. Eissa. 1995. A phase 1 study, in cystic fibrosis patients, of the safety, toxicity, and biological efficacy of a single administration of a replication deficient, recombinant adenovirus carrying the cDNA of the normal cystic fibrosis transmembrane conductance regulator gene in the lung. Hum. Gene Ther. 6:643-666.

40. Wilson, J., J. Engelhardt, M. Grossman, R. Simon, and Y. Yang. 1994. Gene therapy of cystic fibrosis lung disease using E1 deleted adenoviruses: a phase 1 trial. Hum. Gene Ther. 5:501-519.

41. Welsh, M. J. A. E Smith, J. Zabner, D. P. Rich, S. M. Graham, R. J. Gregory, B. M. Pratt, and R. A. Moscicki. 1994. Cystic fibrosis gene therapy using an adenovirus vector: in vivo safety and efficacy in nasal epithelium. Hum. Gene Ther. 5:209-219.

42. Boucher, R. M. Knowles, L. Johnson, J. Olsen, R. Pickles, J. Wilson, J. Engelhardt, Y. Yang, and M. Grossman. 1994. Gene therapy for cystic fibrosis using E1-deleted adenovirus: a phase 1 trial in the nasal cavity. Hum. Gene Ther. 5:615-639. 
43. Wilmott, R. W., J. Whitsett, and B. Trapnell. 1995. A phase I study of gene therapy of cystic fibrosis utilizing a replication deficient recombinant adenovirus vector to deliver the human cystic fibrosis transmembrane conductance regulator cDNA to the airways. In Federal Register. Vol. 58. 21737-21740.

44. Crystal, R. G., N. G. McElvaney, M. A. Rosenfeld, C.-S. Chu, A. Mastrangeli, J. G. Hay, S. L. Brody, H. A. Jaffe, N. T. Eissa, and C. Danel. 1994. Administration of an adenovirus containing the human CFTR cDNA to the respiratory tract of individuals with cystic fibrosis. Nat. Genet. 8:42-51.

45. Knowles, M. R., K. Hohneker, Z. Q. Zhou, J. C. Olsen, T. L. Noah, P.-C. Hu, M. W. Leigh, J. F. Engelhardt, L. J. Edward, K. Jones, et al. 1995. A double-blind vehicle-controlled study of adenoviral vector mediated gene transfer in the nasal epithelium of patients with cystic fibrosis. N. Engl. J. Med. 333: 823-831.

46. Zabner, J., L. A. Couture, R. J. Gregory, S. M. Graham, A. E. Smith, and M. J. Welsh. 1993. Adenovirus-mediated gene transfer transiently corrects the chloride transport defect in nasal epithelia of patients with cystic fibrosis. Cell. 75:207-216.

47. Yang, Y., F. Nunes, K. Berencsi, E. Gonczol, J. Engelhardt, and J. Wilson. 1994. Inactivation of $E 2 a$ in recombinant adenoviruses improves the prospect for gene therapy in cystic fibrosis. Nat. Genet. 7:362-369.

48. Yang, Y., Q. Li, H. Ertl, and J. Wilson. 1995. Cellular and humoral immune responses to viral antigens create barriers to lung-directed gene therapy with recombinant adenoviruses. J. Virol. 69:2004-2015.

49. Yang, Y., G. Trinchieri, and J. M. Wilson. 1995. Recombinant IL-12 prevents formation of blocking IgA antibodies to recombinant adenovirus and allows repeated gene therapy to mouse lung. Nature Med. 1:890-893.

50. Mastrangeli, A., C. Danel, M. A. Rosenfeld, L. Stratford-Perricaudet, M. Perricaudet, A. Pavirani, J.-P. Lecocq, and R. G. Crystal. 1993. Diversity of airway epithelial cell targets for in vivo recombinant adenovirus-mediated gene transfer. J. Clin. Invest. 91:225-234.

51. Zabner, J., D. M. Petersen, A. P. Puga, S. M. Graham, L. A. Couture, L. D. Keyes, M. J. Lukason, J. A. St. George, R. J. Gregory, A. E. Smith, and M. J. Welsh. 1994. Safety and efficacy of repetitive adenovirus-mediated transfer of CFTR cDNA to airway epithelia of primates and cotton rats. Nat. Genet. 6:7583.

52. Yei, S., N. Mittereder, K. Tang, C. O'Sullivan, and B. C. Trapnell. 1994. Adenovirus-mediated gene transfer for cystic fibrosis: quantitative evaluation of repeated in vivo vector administration to the lung. Gene Ther. 1:192-200.

53. Yei, S., N. Mittereder, S. Wert, J. A. Whitsett, R. W. Wilmott, and B. C. Trapnell. 1994. In vivo evaluation of the safety of adenovirus-mediated transfer of the human cystic fibrosis transmembrane conductance regulator cDNA to the lung. Hum. Gene Ther. 5:731-744.

54. Engelhardt, J., L. Litzky, and J. Wilson. 1994. Prolonged transgene expression in cotton rat lung with recombinant adenoviruses defective in E2a. Hum. Gene Ther. 5:1217-1229.

55. Engelhardt, J., R. Simon, Y. Yang, M. Zepeda, S. Pendleton, B. Doranz, M. Grossman, and J. Wilson. 1993. Adenovirus-mediated transfer of the CFTR gene to lung of nonhuman primates: biological efficacy study. Hum. Gene Ther. 4:759-769.

56. Simon, R., J. Engelhardt, Y. Yang, M. Zepeda, S. Pendleton, M. Grossman, and J. Wilson. 1993. Adenovirus-mediated transfer of the CFTR gene to lung of nonhuman primates: toxicity study. Hum. Gene Ther. 4:771-780.

57. Goldman, M. J., L. Litzky, J. F. Engelhardt, and J. M. Wilson. 1995. Transfer of the CFTR gene to the lung of nonhuman primates with E1 deleted, E2a defective recombinant adenoviruses: a preclinical toxicology study. Hum. Gene Ther. 6:839-851.

58. Bout, A., M. Perricaudet, G. Baskin, J.-L. Imler, B. J. Scholte, A. Pavirani, and D. Valerio. 1994. Lung gene therapy: in vivo adenovirus-mediated gene transfer to rhesus monkey airway epithelium. Hum. Gene Ther. 5:3-10.

59. Brody, S. L., M. Metzger, C. Danel, M. A. Rosenfeld, and R. G. Crystal. 1994. Acute responses of non-human primates to airway delivery of an adenovirus vector containing the human cystic fibrosis transmembrane conductance regulator cDNA. Hum. Gene Ther. 5:821-836.

60. Engelhardt, J., Y. Yang, L. Stratford-Perricaudet, E. Allen, K. Kozarsky, M. Perricaudet, J. Yankaskas, and J. Wilson. 1993. Direct gene transfer of human CFTR into human bronchial epithelia of xenografts with E1-deleted adenoviruses. Nat. Genet. 4:27-34.

61. Yang, Y., J. Engelhardt, and J. Wilson. 1994. Ultrastructural localization of variant forms of CFTR in human bronchial epithelia of xenografts. Am. J. Respir. Cell Mol. Biol. 11:7-15.

62. Zsengeller, Z., S. Wert, W. Hull, X. Hu, S. Yei, B. Trapnell, and J. Whitsett. 1995. Persistence of replication-deficient adenovirus-mediated gene transfer in lungs of immune-deficient (nu/nu) mice. Hum. Gene Ther. 6:457467.

63. Yang, Y., K. U. Jooss, Q. Su, H. C. J. Ertl, and J. M. Wilson. 1995. Immune responses to viral antigens vs. transgene product in the elimination of recombinant adenovirus infected hepatocytes in vivo. Gene Ther. In press.

64. Yang, Y., and J. M. Wilson. 1995. Clearance of adenovirus-infected hepatocytes by MHC class I restricted $\mathrm{CD}^{+}$cytotoxic $\mathrm{T}$ lymphocytes in vivo. J. Immunol. 155:2564-2570.

65. Yang, Y., Z. Xiang, H. C. J. Ertl, and J. M. Wilson. 1995. Upregulation of class I MHC antigens by interferon- $\gamma$ is necessary for the T cell-mediated elimination of recombinant adenovirus infected hepatocytes in vivo. Proc. Natl. Acad. Sci. USA 92:7257-7261.

66. Paul, W. E., and R. A. Seder. 1994. Lymphocyte responses and cytokines. Cell. 76:241-245.

67. Ando, K., T. Moriyama, L. G. Guidotti, S. Wirth, R. D. Schreiber, H. J. Schlicht, S. Huang, and F. V. Chisari. 1993. Mechanisms of class I restricted immunopathology. A transgenic mouse model of fulminant hepatitis. J. Exp. Med. 178:1541-1554.

68. Issekutz, T. B., J. M. Stoltz, and P. V. D. Meide. 1988. Lymphocyte recruitment in delayed-type hypersensitivity. The role of IFN- $\gamma$. J. Immunol. 140:2989-2997.

69. Maraskovsky, E., W.-F. Chen, and K. Shortman. 1989. IL-2 and IFN- $\gamma$ are two necessary lymphokines in the development of cytotoxic T cells. J. Immunol. 143:1210-1214.

70. Wille, A., A. Gessner, H. Lother, and F. Lehmann-Grube. 1989. Mechanism of recovery from acute virus infection. VIII. Treatment of lymphocytic choriomeningitis virus-infected mice with anti-interferon- $\gamma$ monoclonal antibody blocks generation of virus-specific cytotoxic $\mathrm{T}$ lymphocytes and virus elimination. Eur. J. Immunol. 19:1283-1288.

71. Skoskiewicz, M. J., R. B. Colvin, E. E. Schneeberger, and P. S. Russell. 1985. Widespread and selective induction of major histocompatibility complexdetermined antigens in vivo by $\gamma$ interferon. J. Exp. Med. 162:1645-1664.

72. Fellous, M., U. Nir, D. Wallach, G. Merlin, M. Rubinstein, and M. Revel. 1982. Interferon-dependent induction of mRNA for the major histocompatibility antigens in human fibroblasts and lymphoblastoid cells. Proc. Natl. Acad. Sci. USA 79:3082-3086.

73. Barr, D., J. Tubb, D. Ferguson, A. Scaria, A. Lieber, C. Wilson, J. Perkins, and M. A. Kay. 1995. Strain related variations in adenovirally mediated transgene expression from mouse hepatocytes in vivo: comparisons between immunocompetent and immunodeficient inbred strains. Gene Ther. 2:151-155.

74. Mitani, K., F. L. Graham, C. T. Caskey, and S. Kochanek. 1995. Rescue propagation, and partial purification of a helper virus-dependent adenovirus vector. Proc. Natl. Acad. Sci. USA. 92:3854-3858.

75. Wold, W., and L. Gooding. 1991. Region E3 of adenovirus: a cassette of genes involved in host immunosurveillance and virus-cell interactions. Virology. 184:1-8.

76. York, I., C. Roop, D. Andrews, S. Riddell, F. Graham, and D. Johnson 1994. A cystolic herpes simplex virus protein inhibits antigen presentation to $\mathrm{CD}^{+} \mathrm{T}$ lymphocytes. Cell. 77:525-535.

77. Jones, T. R., L. K. Hanson, L. Sun, J. S. Slater, R. M. Stenberg, and A. E. Campbell. 1995. Multiple independent loci within the human cytomegalovirus unique short region down-regulate expression of major histocompatibility complex class I heavy chains. J. Virol. 69:4830-4841.

78. Durie, F. H., T. M. Foy, S. R. Masters, J. D. Laman, and R. J. Noelle 1994. The role of CD40 in the regulation of humoral and cell-mediated immunity. Immunol. Today. 15:406-411.

79. Bluestone, J. A. 1995. New perspectives of CD28-B7-mediated T cell costimulation. Immunity. 2:555-559.

80. Goldman, M. J., and J. M. Wilson. 1995. Expression of $\alpha \mathrm{v} \beta 5$ integrin is necessary for efficient adenovirus-mediated gene transfer in the human airway. J. Virol. 69:5951-5958.

81. Wickham, T. J., P. Mathias, D. A. Cheresh, and G. R. Nemerov. 1993 Integrins $\alpha v \beta 3$ and $\alpha v \beta 5$ promote adenovirus internalization but not virus attachment. Cell. 73:309-319.

82. Ginsberg, H., R. Horswood, R. Chanock, and G. Prince. 1990. Role of early genes in pathogenesis of adenovirus pneumonia. Proc. Natl. Acad. Sci. USA 87:6191-6195.

83. Prince, G., D. Porter, A. Jenson, R. Horswood, R. Chanock, and H. Ginsberg. 1993. Pathogenesis of adenovirus type 5 pneumonia in cotton rats. $J$. Virol. 67:101-111.

84. Ginsberg, H. 1991. A mouse model for investigating the molecular pathogenesis of adenovirus pneumonia. Proc. Natl. Acad. Sci. USA. 88:1651-1655.

85. McCoy, R. D., B. L. Davidson, B. J. Roessler, G. B. Huffnagle, S. L. Janich, T. J. Laing, and R. H. Simon. 1995. Pulmonary inflammation induced by incomplete or inactivated adenoviral particles. Hum. Gene Ther. In press. 